The International

Journal of

Integrated

Engineering

\title{
5G Hairpin and Interdigital Bandpass Filters
}

\author{
Sahar Saleh ${ }^{1 *}$ Widad Ismail $^{2}$, Intan Sorfina Zainal Abidin ${ }^{3}$ Mohd Haizal \\ Jamaluddin $^{4}$
}

${ }^{1,2,3}$ School of Electrical and Electronic Engineering

Universiti Sains Malaysia, Nibong Tebal, Penang, 14300, MALAYSIA

${ }^{4}$ Wireless Communication Centre, Universiti Teknologi Malaysia

Johor Bahru, Johor, 81310, MALAYSIA

*Corresponding Author

DOI: https://doi.org/10.30880/ijie.2020.12.06.009

Received 10 September 2019; Accepted 03 June 2020; Available online 02 July 2020

\begin{abstract}
At two low 5G frequency bands: $3.7 \mathrm{GHz}-4.2 \mathrm{GHz}$ and $5.975 \mathrm{GHz}-7.125 \mathrm{GHz}$, Hairpin Bandpass Filter (HPBF) and Interdigital Bandpass Filter (IBF) are designed and simulated in this paper. Both filters show good results in terms of matching and transmission responses with a wide bandwidth through the two frequency bands. HPBF with simple design resulted in good return and insertion losses, $<-10.43 \mathrm{~dB}$ and $-0.63 \mathrm{~dB}$, and $<-14.48 \mathrm{~dB}$ and $-0.46 \mathrm{~dB}$ through frequency bands: $3.51 \mathrm{GHz}-4.27 \mathrm{GHz}$ and $5.58 \mathrm{GHz}-7.24 \mathrm{GHz}$, respectively. In addition to good filter response that IBF provides, it supports high order second harmonics suppression. The simulated $S_{11}$ and $S_{12}$ of this filter are $<-11.15 \mathrm{~dB}$ and $-0.63 \mathrm{~dB}$ with out of band rejection up to $11.12 \mathrm{GHz}$ through the frequency band $3.56 \mathrm{GHz}$ $-4.25 \mathrm{GHz}$. Furthermore, at the second frequency band IBF is designed with two different grounding via hole radii (rVia), case $1: \mathrm{rVia}=0.4 \mathrm{~mm}$ and case $2: \mathrm{rVia}=0.7 \mathrm{~mm}$. For both cases, the designed filter shows good results with high order second harmonics suppression up to $18.33 \mathrm{GHz}$ and $18.96 \mathrm{GHz}$. In this paper, High Frequency Structure Simulator (HFSS) software is used to carry out the simulation.
\end{abstract}

Keywords: Hairpin Bandpass Filter (HPBF), Interdigital Bandpass Filter (IBF), high order second harmonics suppression, 5G, HFSS

\section{Introduction}

Filters play important role in many RF/Microwave applications in which they are used to get different responses ( band-pass, band-stop, low-pass, and high-pass) [1]. Hairpin Bandpass Filter (HPBF) is simply constructed by folding the $\lambda / 2$ resonators of the parallel- coupled filter, to get the U shape [2]. HPBF has been used in many applications for different frequencies. In [3], $5.78 \mathrm{GHz}$ with $10 \% \mathrm{BW}$ HPBF was designed to work for unlicensed WiMAX. Superior harmonics suppression in the response of HPBF is obtained in [4] by adding different Defected Microstrip Structure (DMS) to the filter's resonators. The resulted suppressions were $25 \mathrm{~dB}$ and $40 \mathrm{~dB}$ for the second and the third harmonics. Authors in[5], designed a compact HPBF for $923 \mathrm{MHz}$ RFID application. The compactness was $37 \%$ and it was achieved using via hole grounding. Plackett-Burman Design of Experiment methodology (DOE) was applied in designing $2.4 \mathrm{GHz}$ HPBF for further optimization. The resulted insertion and return loss of this filter were $61 \%$ and $15 \%$ improved from the one designed with Gensys software. $2 \mathrm{GHz}-4 \mathrm{GHz}$ HPBF was designed in [6] for satellite application. HPBF with Defected Ground Structure (DGS) for radar application was designed in [7]. In addition, this filter showed better performance with aluminum casing. In [8], X- band HPBF was designed for radar navigation. Authors in [9], designed a millimeter wave HPBF $(30 \mathrm{GHz}$ ) on Liquid Crystal Polymer Substrate using Inkjet Printing Technology. The measured insertion and return loss at $30.4 \mathrm{GHz}$ were 2.41 and $18.9 \mathrm{~dB}$, respectively. Spurious harmonic response suppression was obtained by using nonuniform coupled line resonators to design $34 \mathrm{GHz}$ in [10]. HPBF with tunable center frequency 
$650 \mathrm{MHz}$ to $920 \mathrm{MHz}$ and bandwidth $25 \mathrm{MHz}$ and $85 \mathrm{MHz}$ was designed in [11] using Screen Printed Ferroelectric Varactors. Authors in [12], designed three different $20 \mathrm{GHz}$ HPBF with different feeding techniques.

Interdigital Bandpass Filter (IBF) is considered compact because of its $\lambda / 4$ resonators length as compared to HPBF $\lambda / 2$ resonators length. Furthermore, it supports high order second harmonics suppressions since their center frequency usually occurs around three times the center frequency of the desired band [2]. IBF has been used in many applications. In [13] , $900 \mathrm{MHz}$ IBF was designed. The designed filter supported up to $3^{\text {rd }}$ harmonic suppression using under-coupled quarter-wavelength resonator pair. $2.25 \mathrm{GHz}$ IBF with multilayer folded quarter-wavelength resonators was proposed in[14]. Based on CMOS technology, high frequency $55 \mathrm{GHz}$ millimeter wave IBF was designed in [15]. Authors in [16] designed a compact interdigital filter operating at L band via changing the filter coupling structure. In [17], spurlines were used to achieve up to $8 \mathrm{GHz}$ in designing seventh-order IBF. Sixth-order $2.25 \mathrm{GHz}$ IBF was proposed in [18] to meet electromagnetic interference (EMI) or electromagnetic compatibility (EMC) issues requirements. Authors in [19], designed 2.4 GHz IBF. Ninth-order IBF with LTE duplexer band 28 was proposed in [20]. Aggressive space mapping was used to design two-layer K-band IBF in [21]. After seven iterations, good filter response was obtained and this reflects a small run time simulation as compared to the full-wave electromagnetic simulation software.

On October 24, 2018, the Federal Communication Commission (FCC) has proposed two frequency bands below 24 GHz licensed (C-Band: $3.7 \mathrm{GHz}-4.2 \mathrm{GHz}$ ) and unlicensed $(5.925 \mathrm{GHz}-6.425 \mathrm{GHz}, 6.525 \mathrm{GHz}-6.875 \mathrm{GHz}$ and 6.875 $\mathrm{GHz}-7.125 \mathrm{GHz}$ bands(totally $5.925 \mathrm{GHz}-7.125 \mathrm{GHz}$ )) spectrum for $5 \mathrm{G}$ technology [22]. In this paper, HPBF and IBF are designed at these two frequency bands, which is considered as a contribution at $5 \mathrm{G}$ technology. Furthermore, both filters provide wide bandwidth as compared to the other filters in the literature. Take in consideration that the chosen substrate material in this study is Rogers $\operatorname{RO} 4003 \mathrm{C}\left(\varepsilon_{r}=3.55\right.$ and $\left.\mathrm{h}=0.813 \mathrm{~mm}\right)$.

\section{5G 3.95 GHz Bandpass Filters}

\subsection{Hairpin Bandpass Filter}

Based on the design equations in [2], 3.95 GHz HPBF is deigned. Table 1 indicates all the calculated and optimized parameters of the filter, where $\mathrm{L}_{\mathrm{res}}, \mathrm{W}_{\text {res }}, \mathrm{S}, \mathrm{L}_{\mathrm{t}}, \mathrm{L}_{\mathrm{p} 1}, \mathrm{~L}_{\mathrm{p} 2}$ and $\mathrm{W}_{\mathrm{p}}$ are the length of the resonator, width of the resonator, the space between two adjacent resonators, tapping length, length of the first and second port and width of the ports, respectively. Figure 1 shows the layout of the designed $3.95 \mathrm{GHz}$ HPBF. The simulated insertion loss is less than $-10 \mathrm{~dB}$ and simulated insertion loss is around $-0.79 \mathrm{~dB}$ at center frequency, $\mathrm{Fc}=3.89 \mathrm{GHz}$ through the frequency band $(3.57$ $\mathrm{GHz}-4.32 \mathrm{GHz}$ ) as shown in Fig. 2. In addition, one can observe that the proposed $3.95 \mathrm{GHz}$ HPBF can support up to only $7.8 \mathrm{GHz}$ harmonics suppression which is not as high as $3.95 \mathrm{GHz}$ IBF can support and this will be explained in the next section.

Table 1 - Calculated and Optimized parameters of $3.95 \mathrm{GHz}$ HPBF

\begin{tabular}{ccc}
\hline Parameters & Calculated & Optimized \\
\hline $\mathbf{L}_{\text {res }}(\mathbf{m m})$ & 23.268 & 23 \\
$\mathbf{W}_{\text {res }}(\mathbf{m m})$ & 0.595 & 0.45 \\
$\mathbf{S}(\mathbf{m m})$ & 0.63 & 0.3 \\
$\mathbf{L}_{\mathbf{t}}(\mathbf{m m})$ & 2.06 & 2.7 \\
$\mathbf{L}_{\mathbf{p} 1}(\mathbf{m m})$ & - & 3 \\
$\mathbf{L}_{\mathbf{p} 2}(\mathbf{m m})$ & & 3 \\
$\mathbf{W} \mathbf{p}(\mathbf{m m})$ & 1.819 & 1.5 \\
\hline
\end{tabular}




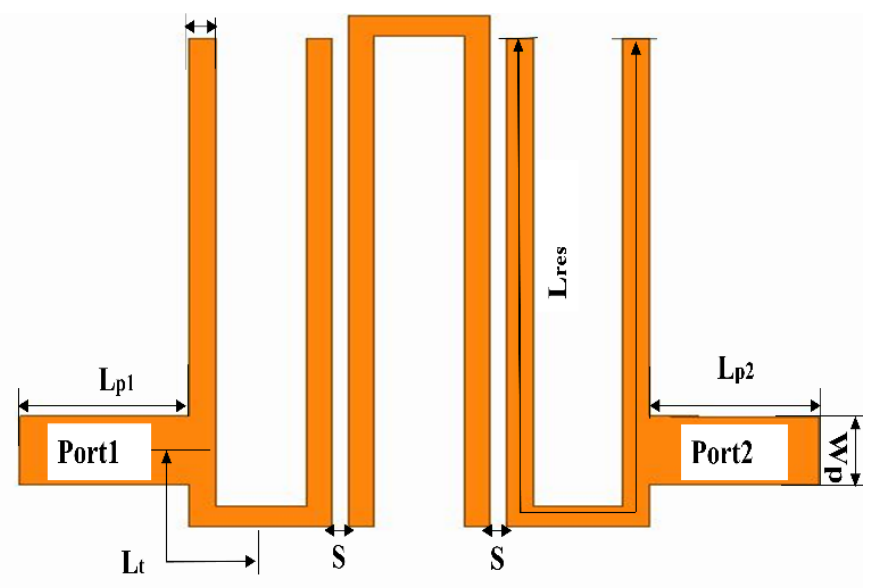

Fig. 1 - Configuration of $3.95 \mathrm{GHz}$ HPBF

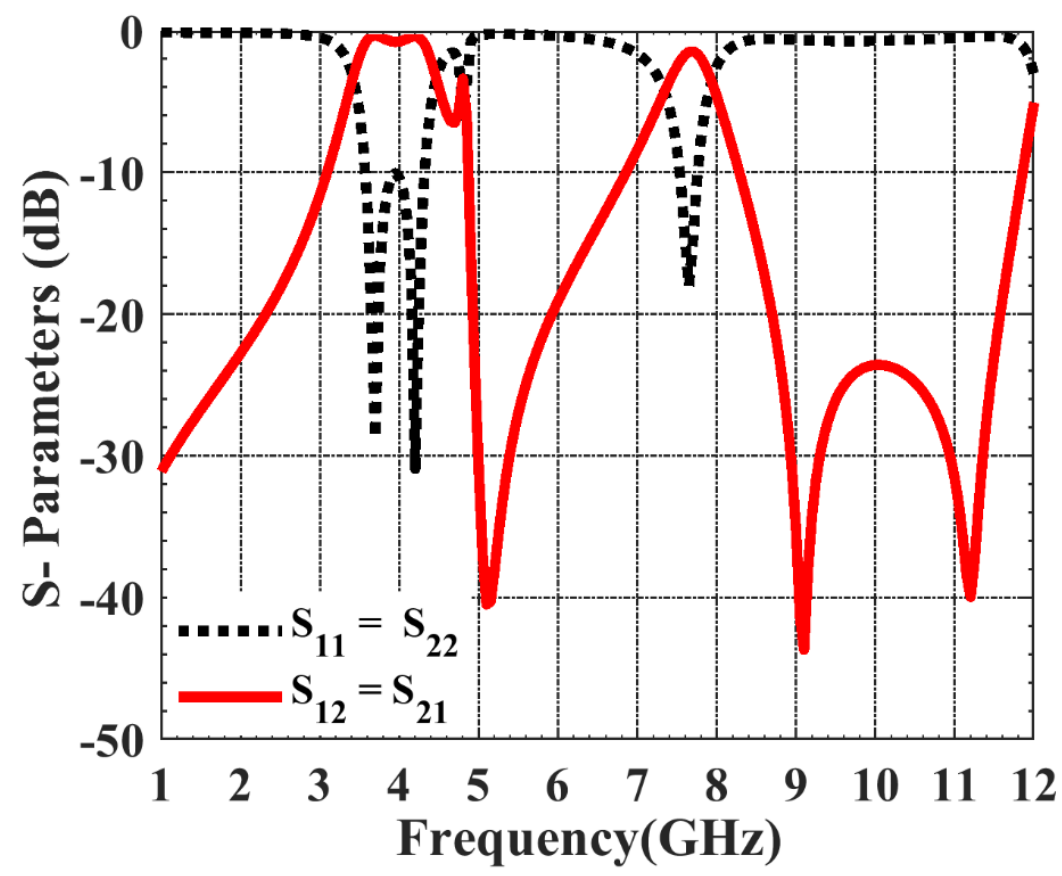

Fig. 2 - Simulated S-Parameters of the proposed 3.95 HPBF

\subsection{Interdigital Bandpass Filter}

The same procedure and design equations in [2] are used to design the three order symmetrical coupled line 3.95 GHz. The calculated and optimized parameters of this filter are shown in Table 2, where $\mathrm{L}_{\text {res } 1}, \mathrm{~L}_{\text {res } 2}, \mathrm{rVia}$ are the length of the first, second resonators and radius of the via hole, respectively. The designed filter is shown in Fig. 3. 
Table 2 - Calculated and optimized parameters of 3.95 GHz interdigital filter

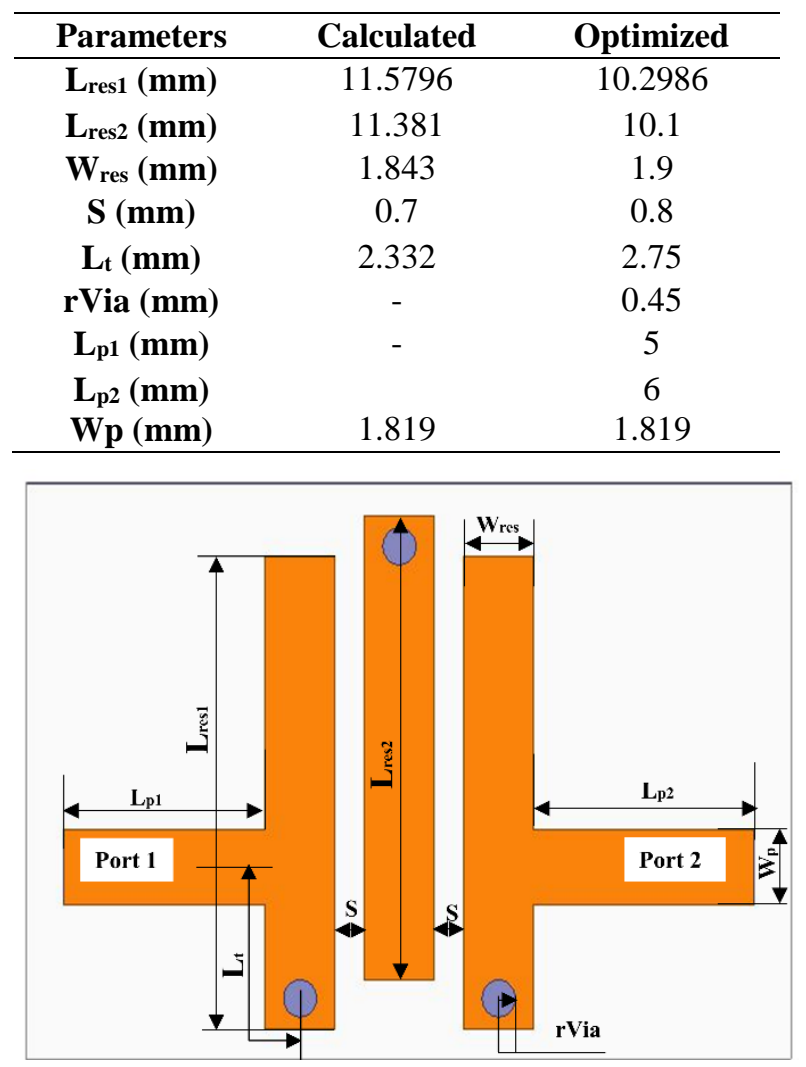

Fig. 3 - Configuration of 3.95 GHz interdigital filter

The simulated reflection and transmission coefficients are demonstrated in Fig. 4. At $3.56 \mathrm{GHz}-4.25 \mathrm{GHz}, \mathrm{S}_{11}=$ $\mathrm{S}_{22}$ is $<-11.15 \mathrm{~dB}$ and $\mathrm{S}_{12}=\mathrm{S}_{21}$ is approximately $-0.63 \mathrm{~dB}$ which indicates a good filter response. Up to $11.77 \mathrm{GHz}$ high order second harmonics can be obtained using this filter as shown in Fig.4 which better than that of 3.95 GHz HPBF (only up to $7.8 \mathrm{GHz}$ ). So, $3.95 \mathrm{GHz}$ IBF is preferred to be used with devices with wide bandwidth for example with Ultra Wideband (UWB) antenna to have a notch at this narrow band $(3.7 \mathrm{GHz}-4.2 \mathrm{GHz})$.

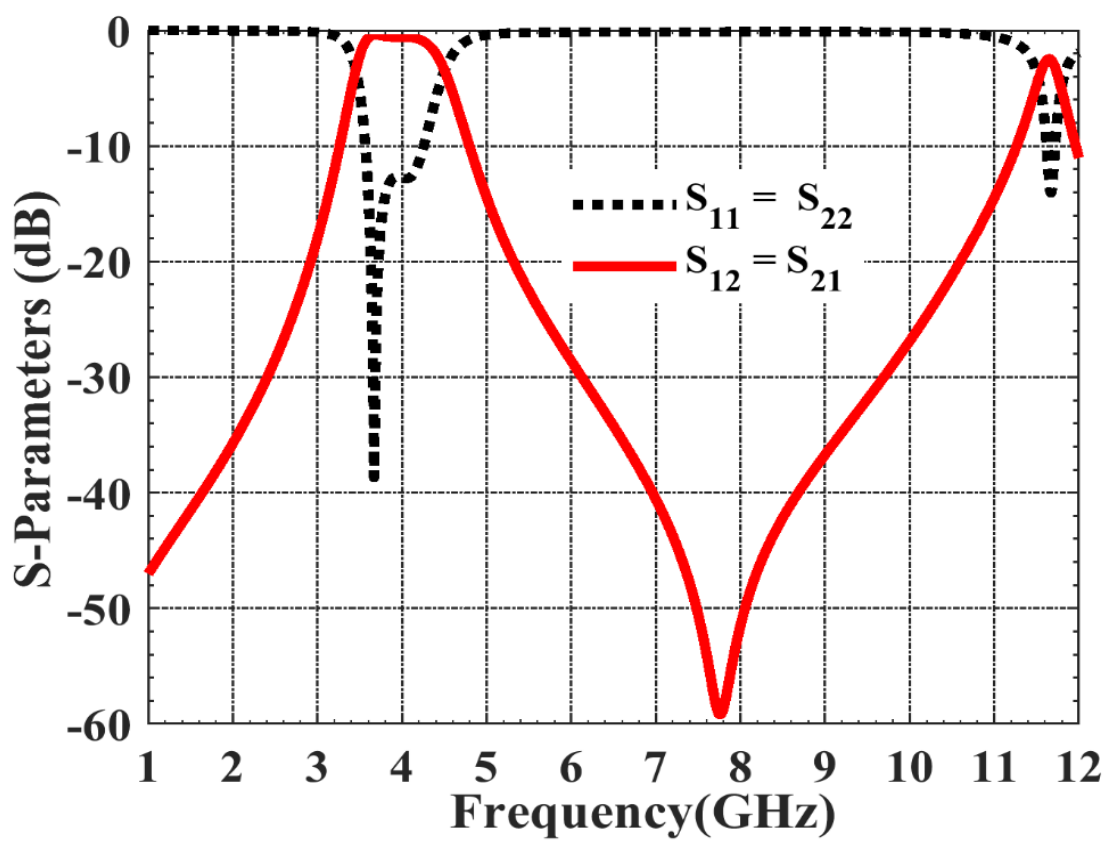

Fig. 4 - Simulated S-Parameters of the proposed 3.95 IBF 


\section{5G 6.55 GHz Bandpass Filters}

\subsection{Hairpin Bandpass Filter}

All the calculated and optimized parameters of $6.55 \mathrm{GHz}$ HPBF are indicated in Table 3. The configuration of the proposed UTL HPBF is shown in Fig.5. The designed filter shows good filter response through the desired frequency band. The simulated $S_{11}=S_{22}$ is less than $-19 \mathrm{~dB}$ and $S_{12}=S_{21}$ is around $-0.5 \mathrm{~dB}$ at Fc $=6.61 \mathrm{GHz}$ through the frequency band $5.87 \mathrm{GHz}-7.35 \mathrm{GHz}$ as shown in Fig. 6. In addition, harmonics at $11.1 \mathrm{GHz}$ are not $100 \%$ suppressed. However, IBF at the same frequency band can support up to $19.1 \mathrm{GHz}$ and $18.35 \mathrm{GHz}$ high order harmonics suppressions.

Table 3 - Calculated and Optimized parameters of $6.55 \mathrm{GHz}$ HPBF

\begin{tabular}{ccc}
\hline Parameters & Calculated & Optimized \\
\hline $\mathbf{L}_{\text {res }}(\mathbf{m m})$ & 14.325 & 15.524 \\
$\mathbf{W}_{\text {res }}(\mathbf{m m})$ & 0.5 & 0.6 \\
$\mathbf{S}(\mathbf{m m})$ & 0.65 & 0.3 \\
$\mathbf{L}_{\mathbf{t}}(\mathbf{m m})$ & 1.267 & 2.9 \\
$\mathbf{L}_{\mathbf{p} 1}=\mathbf{L}_{\mathbf{p} 2}(\mathbf{m m})$ & - & 4 \\
$\mathbf{W}_{\mathbf{p}}(\mathbf{m m})$ & 1.819 & 1.819 \\
\hline
\end{tabular}

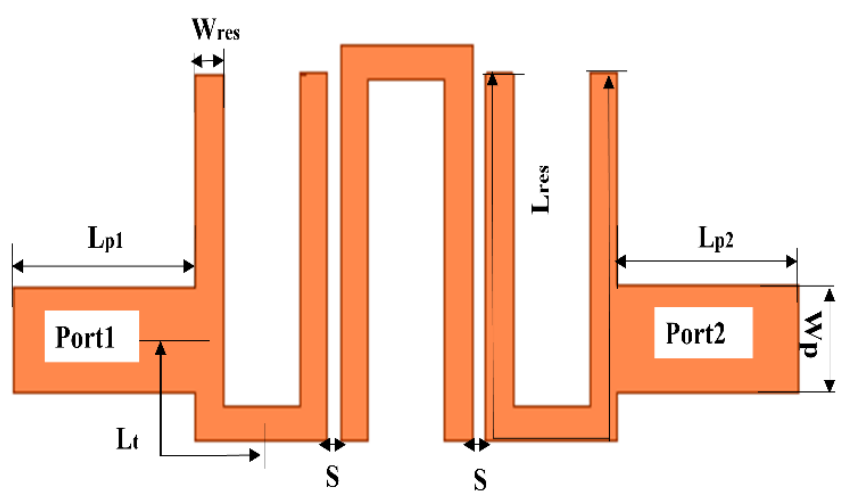

Fig. 5 - Configuration of $6.55 \mathrm{GHz}$ HPBF

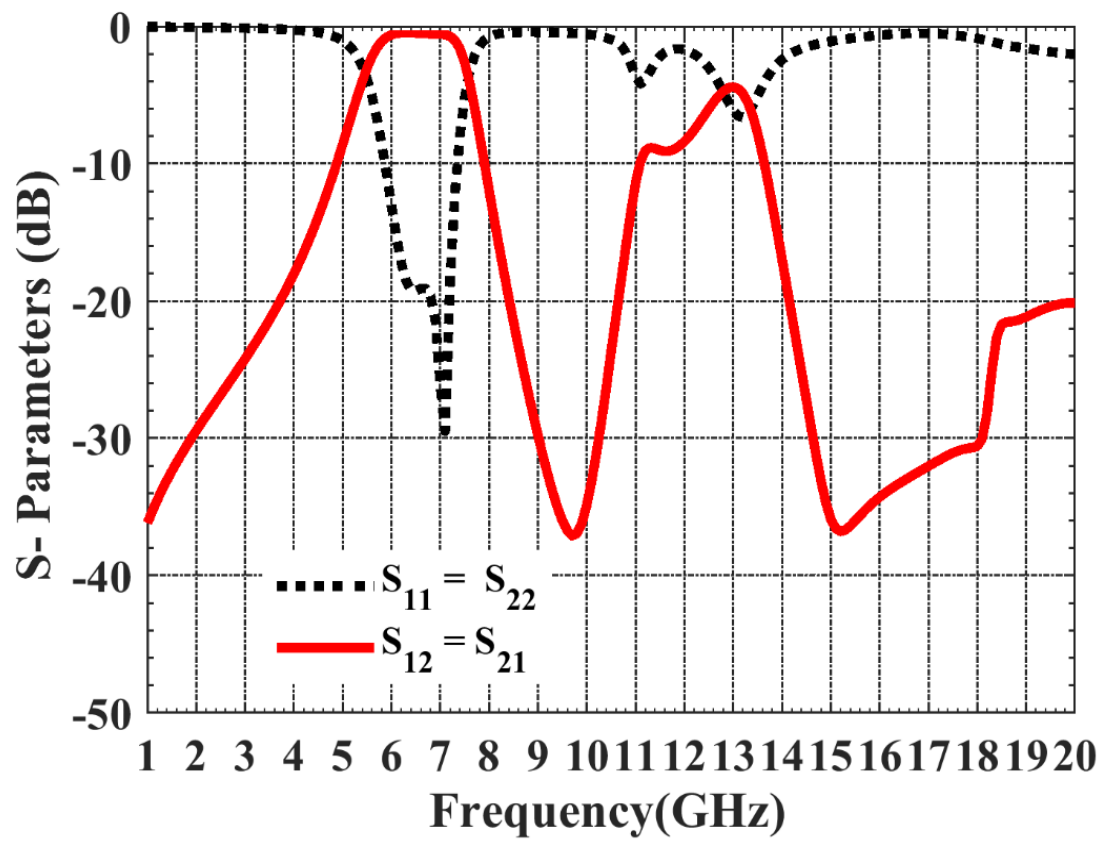

Fig. 6 - Simulated S-Parameters of the proposed 6.55 HPBF 


\subsection{Interdigital Bandpass Filter}

Table 4 below indicates all the calculated and optimized parameters $6.55 \mathrm{GHz}$ IBF. Two different grounding via hole radii (i.e. different resonators width) are used in design this filter: Case 1 with $\mathrm{rVia}=0.4 \mathrm{~mm}$ and $\mathrm{W}_{\text {res }}=1.6 \mathrm{~mm}$ and Case 2 with $\mathrm{rVia}=0.75 \mathrm{~mm}$ and $\mathrm{W}_{\text {res }}=2.3 \mathrm{~mm}$. The configuration of the designed $6.55 \mathrm{IBF}$ is shown in Fig. 7 and 8 for case 1 and case 2 , respectively.

Table 4 - Calculated and Optimized parameters of $6.55 \mathrm{GHz}$ IBF

\begin{tabular}{ccc}
\hline Parameters & Calculated & Optimized \\
\hline Lres1 $(\mathbf{m m})$ & 7.0382 & 6.2282 \\
Lres2 $(\mathbf{m m})$ & 6.81 & 6 \\
Wres $(\mathbf{m m})$ & 2.245 & Case1: 1.6 \& Case2: 2.3 \\
S $(\mathbf{m m})$ & 0.665 & Case1: 0.35 \& Case2: 0.4 \\
$\mathbf{L}_{\mathbf{t}}(\mathbf{m m})$ & 1.9 & 2.4 \\
rVia $(\mathbf{m m})$ & - & Case1: 0.4 \& Case2: 0.75 \\
$\mathbf{L}_{\mathbf{p} 1}(\mathbf{m m})$ & - & 4.5 \\
$\mathbf{L}_{\mathbf{p} 2}(\mathbf{m m})$ & & 4.5 \\
$\mathbf{W}_{\mathbf{p}}(\mathbf{m m})$ & 1.819 & 1.78 \\
\hline
\end{tabular}

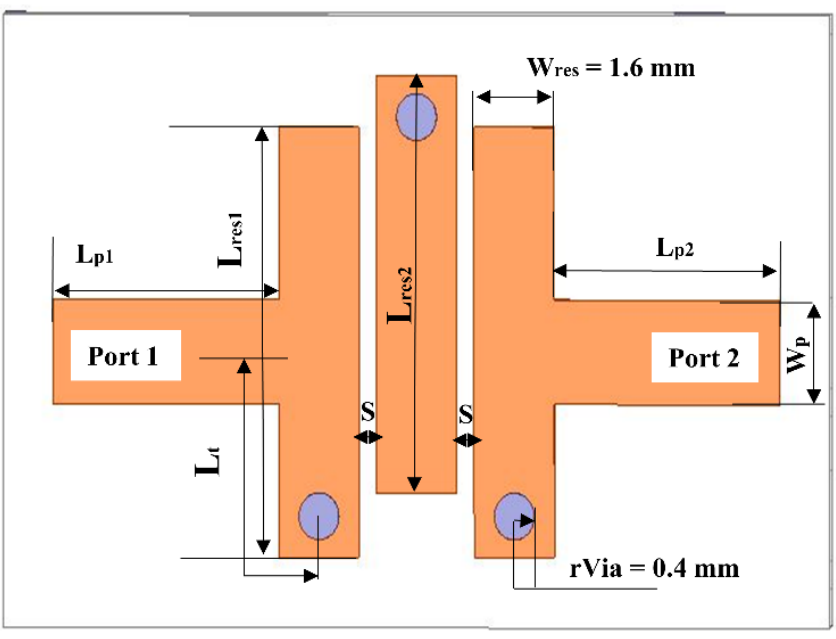

Fig. 7 - Configuration of 6.55 GHz IBF (Case1)

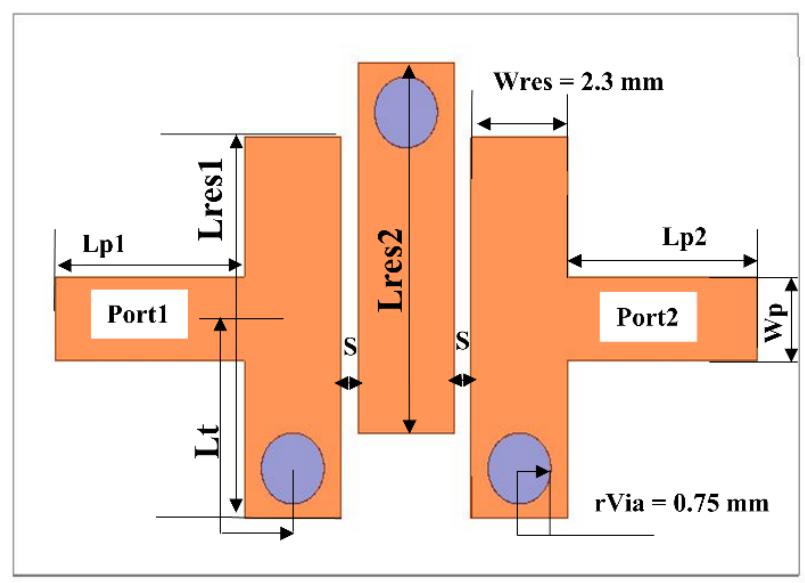

Fig. 8 - Configuration of $6.55 \mathrm{GHz}$ IBF (Case2) 


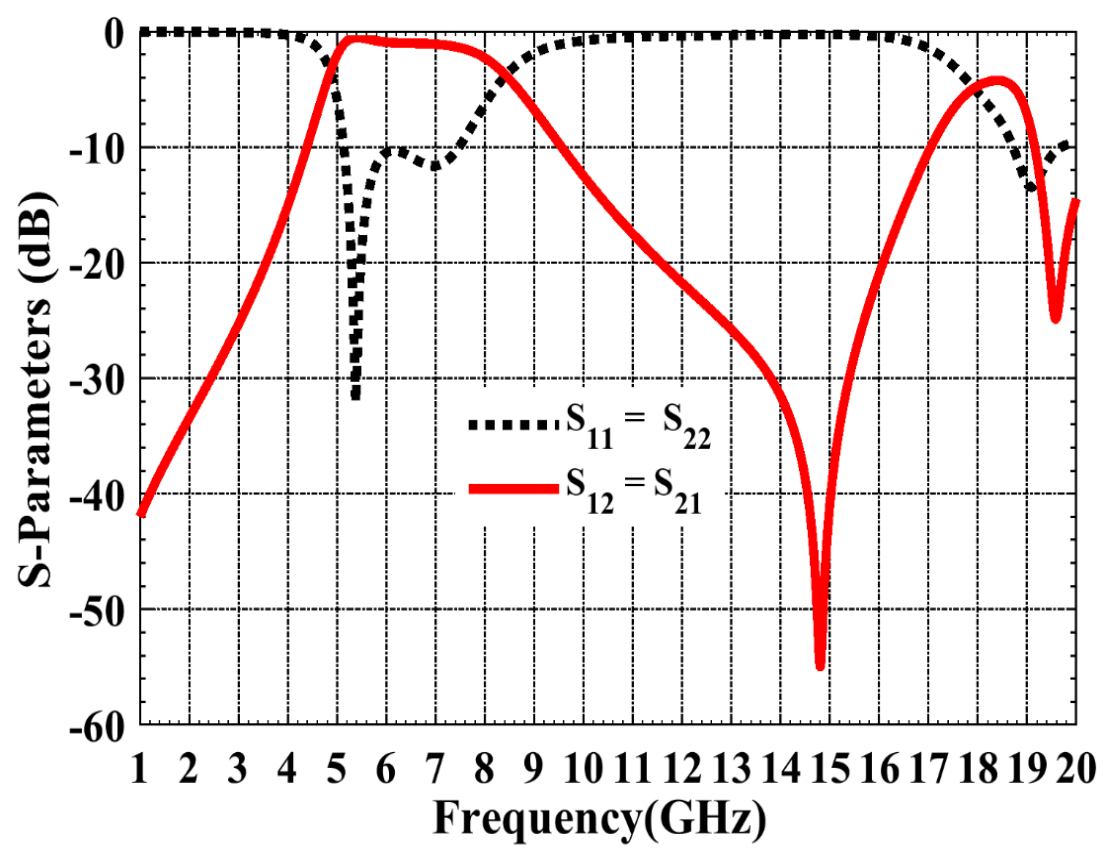

Fig. 9 - Simulated S-Parameters of the proposed 6.55 IBF (Case1)

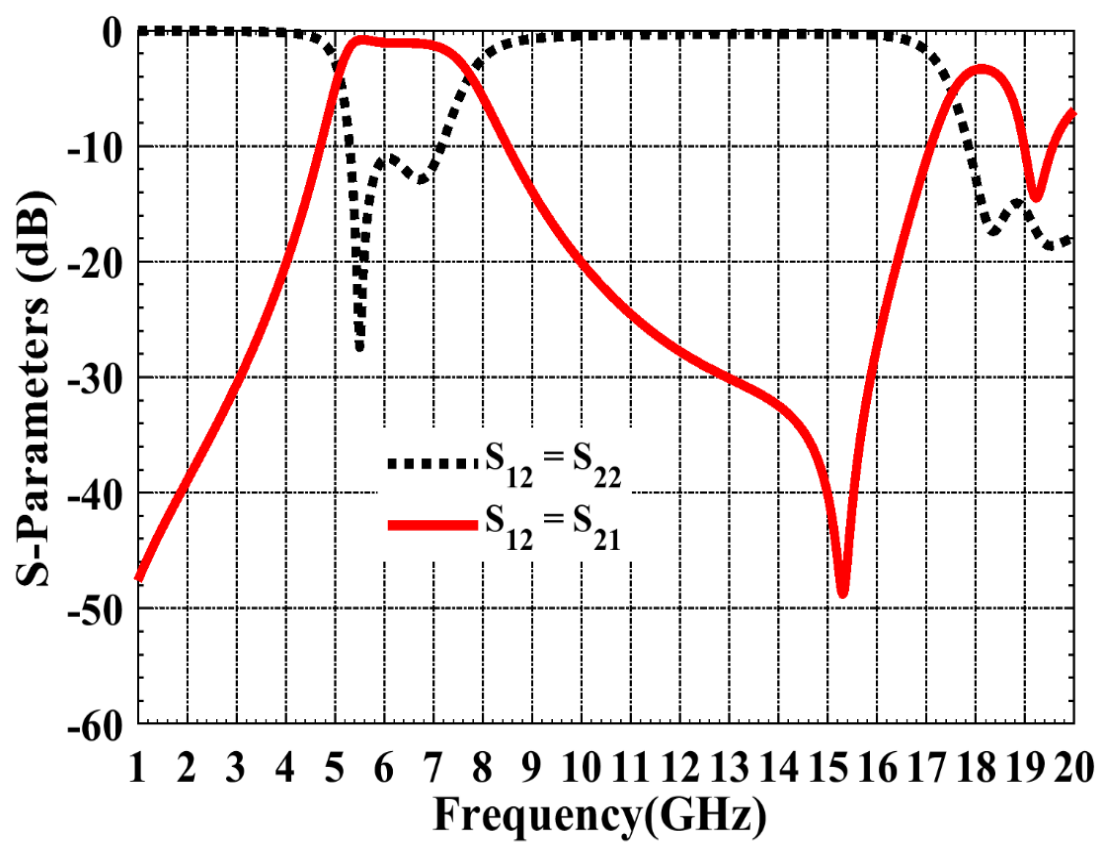

Fig. 10 - Simulated S-Parameters of the proposed 6.55 IBF (Case2)

The simulated filter responses for both cases are shown in Fig. 9 and Fig. 10 above. From Fig. 9 through the frequency band $5.14 \mathrm{GHz}-7.47 \mathrm{GHz}, \mathrm{S}_{11}=\mathrm{S}_{22}$ is below $-10.32 \mathrm{~dB}$ and $\mathrm{S}_{12}=\mathrm{S}_{21}$ is approximately $-1 \mathrm{~dB}$ at Fc $=6.31 \mathrm{GHz}$ in addition to up to $19.1 \mathrm{GHz}$ out of band harmonics suppression. On the other hand, for case 2 the filter response is better than that of case 1 where the reflection coefficient $\mathrm{S}_{11}=\mathrm{S}_{22}$ is below $-11.05 \mathrm{~dB}$ at the frequency bands $5.3 \mathrm{GHz}-7.164 \mathrm{GHz}$ with high order second harmonic suppression up to $18.35 \mathrm{GHz}$ and the transmission coefficient is around $-1.09 \mathrm{~dB}$ at the center frequency $6.25 \mathrm{GHz}$. Generally, the designed $6.55 \mathrm{GHz}$ IBF at the two different via hole radii has good -10 impedance matching. However, its preferable to choose rVia which will be suitable with the calculated $\mathrm{W}_{\text {res. }}$. 
Finally, a comparison to the other HPBFs and IBFs designed at different frequency ranges in the literature is highlighted in Table 5. As it is shown from the table, the proposed 5G HPBF and IBF provide wider bandwidth at the two frequency bands with good impedance matching and transmission response.

Table 5 - Comparison to other HPBFs and IBFs in the literature

\begin{tabular}{|c|c|c|c|c|c|c|c|}
\hline Ref. & $\begin{array}{l}\text { Substrate } \\
\mathbf{h}(\mathbf{m m}) / \\
\varepsilon \mathbf{r} \\
\end{array}$ & order & $3 \mathrm{~dB}$ FBW & $\begin{array}{l}\text { BW } \\
\text { GHz }\end{array}$ & $\begin{array}{c}\text { FC } \\
\text { GHz }\end{array}$ & $\begin{array}{l}S_{11}=S_{22} \\
(d B)\end{array}$ & $S_{12}=S_{21}(d B)$ \\
\hline \multirow{3}{*}{ This work (HPBF) } & & & $\begin{array}{c}18.99 \% \\
\text { at } 3.57 \mathrm{GHz}-4.32 \mathrm{GHz}\end{array}$ & 0.75 & 3.95 & $<-10$ & -0.79 \\
\hline & & & $\begin{array}{c}22.39 \% \\
\text { at } 3.57 \mathrm{GHz}-4.32 \mathrm{GHz}\end{array}$ & 1.48 & 6.61 & $<-19$ & -0.5 \\
\hline & $\begin{array}{l}0.813 \\
13.55\end{array}$ & 3 & $\begin{array}{c}17.65 \% \\
\text { at } 3.56 \mathrm{GHz}-4.25 \mathrm{GHz}\end{array}$ & 0.69 & 3.91 & $<-11.15$ & -0.63 \\
\hline \multirow[t]{2}{*}{ This work (IBF) } & & & $\begin{array}{c}\text { Case } 1: 39.93 \% \\
\text { at } 5.14 \mathrm{GHz}-7.47 \mathrm{GHz}\end{array}$ & 2.33 & 6.31 & $<-10.32$ & -1 \\
\hline & & & $\begin{array}{c}\text { Case } 2: 29.92 \% \text { at } 5.3 \\
\mathrm{GHz}-7.16 \mathrm{GHz}\end{array}$ & 1.86 & 6.23 & $<-11.05$ & -1.09 \\
\hline [3] & $1.52 / 2.2$ & 5 & $\begin{array}{c}0.004 \% \\
\text { at } 920 \mathrm{MHz}-924 \mathrm{MHz}\end{array}$ & 0.922 & 0.922 & -18 & -6.65 \\
\hline [5] & $0.508 / 2.23$ & 3 & $\begin{array}{c}13.03 \% \\
\text { at } \quad 5.23 \mathrm{GHz}-5.96 \mathrm{GHz}\end{array}$ & 0.97 & 5.6397 & -45.91 & 0 \\
\hline [7] & $0.381 / 9.8$ & 5 & $\begin{array}{c}6.67 \% \\
\text { at } 2.9 \mathrm{GHz}-3.1 \mathrm{GHz}\end{array}$ & 0.2 & 3 & -29.98 & -0.76 \\
\hline [8] & $1.58 / 2.2$ & 5 & $\begin{array}{c}1.07 \% \\
\text { at } 9.25 \mathrm{GHz}-9.35 \mathrm{GHz}\end{array}$ & 0.1 & 9.3 & -21.67 & -0.41 \\
\hline [10] & $\begin{array}{l}0.127 \\
/ 2.94\end{array}$ & 3 & $\begin{array}{c}3.84 \% \\
\text { at } 33.2 \mathrm{GHz}-34.5 \mathrm{GHz}\end{array}$ & 1.3 & 33.85 & $<-12$ & -0.37 \\
\hline [13] & $\begin{array}{l}1.524 \\
13.38\end{array}$ & 3 & $\begin{array}{c}30 \% \\
\text { at } 765 \mathrm{MHz}-1035 \mathrm{MHz}\end{array}$ & 0.27 & 0.9 & $<-20$ & -0.17 \\
\hline [17] & $1.27 / 10.2$ & 5 & $\begin{array}{c}65.54 \% \\
\text { at } 0.99-\mathrm{GHz} 1.96 \mathrm{GHz}\end{array}$ & 0.97 & 1.48 & $<-11.24$ & -0.14 \\
\hline [21] & $\begin{array}{l}0.4 / 11.9 \\
\text { (two } \\
\text { layers) }\end{array}$ & 6 & $\begin{array}{c}7.84 \% \\
\text { at } 19.6-21.2 \mathrm{GHz}\end{array}$ & 1.6 & 20.4 & $<-15$ & -1.2 \\
\hline
\end{tabular}

\section{Conclusions}

Two different 5G bandpass filters at two different frequency bands, 3.7 GHz - 4.2 GHz and 5.975 GHz $-7.125 \mathrm{GHz}$ are designed in this paper. The two filters are, Hairpin Bandpass Filter (HPBF) and Interdigital Bandpass Filter (IBF) and they can be used in $5 \mathrm{G} \mathrm{RF}$ front end wireless communication applications, especially in filtering and reconfigurable antennas. Both filters provide wide bandwidth, good $-10 \mathrm{~dB}$ impedance matching and good transmission coefficients through the two frequency bands. Furthermore, designing HPBF and IBF at these two-low frequency 5G bands is considered as a contribution. IBF at $(5.975 \mathrm{GHz}-7.125 \mathrm{GHz})$ is designed with two different ground via hole radii (case $1: \mathrm{rVia}=0.4 \mathrm{~mm}$ and case $2: \mathrm{rVia}=0.75 \mathrm{~mm}$ ) with good resulted reflection and transmission coefficients for both cases. 
IBF at two frequency bands outperforms HPBF in terms of high order second harmonics suppression in which it supports up to $11.77 \mathrm{GHz}$ and $19.1 \mathrm{GHz}$ harmonic suppression at the frequency bands $3.56 \mathrm{GHz}-4.25 \mathrm{GHz}$ and $5.3 \mathrm{GHz}-7.164$ $\mathrm{GHz}$, respectively. Further enhancement can be applied to these $5 \mathrm{G}$ filters to reduce their circuit area to be compatible with the modern communication system. In addition, many techniques can be used to overcome the second harmonic problem in 5G HPBF.

\section{References}

[1] Pozar. D. M. (2012). Microwave engineering (4th ed.). New Jersey: John Wiley \& Sons

[2] Hong. J .-S. G. \& Lancaster. M. J. (2011). Microstrip filters for RF/microwave applications (2nd ed.). New Jersey: John Wiley \& Sons

[3] Zulkifli. F. Y., Saputra. R, \& Rahardjo. E. T. (2011). Microstrip Hairpin Bandpass Filter Using Via Ground Holes for $923 \mathrm{MHz}$ RFID Application, International Symposium on Antennas and Propagation, South Korea Jeju, (pp. 1-4)

[4] Naser-Moghadasi. M., Alamolhoda, M., \& Rahmati. B. (2011). Spurious response suppression in hairpin filter using DMS integrated in filter structure. Progress In Electromagnetics Research,18, 221-229

[5] Wahab. N. A., Muhamad. W. N. W., Hamzah. M. M. A. M., Sarnin. S. S., \& Naim. N. F. (2010). Design a microstrip hairpin band-pass filter for 5GHZ unlicensed WiMAX, International Conference on Networking and Information Technology, Manila, Philippines, (pp. 183-186)

[6] Kavitha. K. \& Jayakumar. M. (2018). Design and Performance Analysis of Hairpin Bandpass Filter for Satellite Applications. Procedia computer science, 143, 886-891

[7] Ismail. N., Gunawan.T. S., Praludi. T., \& Hamidi. E. A., (2018). Design of microstrip hairpin bandpass filter for 2.9 $\mathrm{GHz}-3.1 \mathrm{GHz}$ s-band radar with defected ground structure. Malaysian Journal of Fundamental and Applied Sciences, $14,4,448-455$

[8] Adli. B., Mardiati. R., \& Maulana.Y. Y. (2018). Microstrip Hairpin Bandpass Filter for X-Band Radar Navigation Telematics, 4th International Conference on Wireless and Design of. Nusa Dua, Indonesia, (pp. 1-6)

[9] Kao. H-1., Cho. C.-L., Dai. X., Yeh. C-S., Zhang. X.-Y., Chang. L-C., et al. (2013). Hairpin bandpass filter on liquid crystal polymer substrate using inkjet printing technology, IEEE MTT-S International Microwave Symposium Digest, Seattle, WA, USA, (pp. 1-4)

[10] Shaman. H., Almorqi. S., Haraz. O., \& Alshebeili.S. (2014). Hairpin microstrip bandpass filter for millimeter-wave applications, Mediterranean Microwave Symposium, Marrakech, Morocco, (pp. 1-4)

[11] Schuster. C., Wiens. A., Schüßler. M., Kohler. C ., Binder. J., \& Jakoby. R. (2016). Hairpin bandpass filter with tunable center frequency and tunable bandwidth based on screen printed ferroelectric varactors, 46th European Microwave Conference, London, UK, (pp. 1425-1428)

[12] Ono. S., \& Wada. K. (2018). Design and Fabrication of 3-Pole BPF Configured by Hairpi Resonators and Different Types of Coupling and Feed Types at $20 \mathrm{GHz}$, Asia-Pacific Microwave Conference, Kyoto, Japan, (pp. 1363-1365)

[13] Ting. S.-W., Tam. K.-W., \& Martins. R. P. (2004). Novel interdigital microstrip bandpass filter with improved spurious response, IEEE International Symposium on Circuits and Systems, Vancouver, BC, Canada, (pp. I-984)

[14] Mu. Y., Ma. Z., \& Xu. D. (2005). A novel compact interdigital bandpass filter using multilayer cross-coupled folded quarter-wavelength resonators. IEEE microwave and wireless components letters, 15, 12, 847-849

[15] Yang. B., Skafidas. E., \& Evans. R. (2007). Design of integrated millimetre wave microstrip interdigital bandpass filters on CMOS technology, European Microwave Conference, Munich, Germany, (pp. 680-683)

[16] Jia. X., Na.Y., Bingxia. S., \& Quanming. Z. (2009). The miniaturization design of microstrip interdigital bandpass filter, 2nd International Conference on Power Electronics and Intelligent Transportation Systempp. Shenzhen, China, (pp. 74-76)

[17] Sahu. B., M. Meshram. K., Singh. S., \& Tripathi. P. (2015). Design of microstrip interdigital bandpass filter with suppression of spurious responses for L-band wireless communication applications, International Conference on Microwave and Photonics, Dhanbad, India, (pp. 1-2)

[18] Sharifi-Tehrani. O. (2017). Design, Simulation and Fabrication of Microstrip Hairpin and Interdigital BPF for 2.25 $\mathrm{GHz}$ Unlicensed Band. Majlesi Journal of Telecommunication Devices, 6, 4, 115-118

[19] Bharathi. R. D., Yamini. J. E., Evangeline. A., \& Narayanan. D. B. (2017). Design and analysis of interdigital microstrip bandpass filter for centre frequency $2.4 \mathrm{GHz}$, 3rd International Conference on Science Technology Engineering \& Management, Chennai, India, (pp. 930-933)

[20] Basavaraju. D., Kumaraswamy. H., Kothari. M., \& Kamat. S. (2017). Interdigital band pass filters for duplexer realization for LTE band 28, International Conference on Intelligent Computing and Control, Coimbatore, India, (pp. 1-4)

[21] Zhang. X., Zhai. Q., Li. Z., Ou. W., \& Ou. Y. (2018). Design of a K-band two-layer microstrip interdigital filter exploiting aggressive space mapping. Journal of Electromagnetic Waves 